\title{
Percepções sobre sustentabilidade ambiental durante pandemia pelo novo Coronavírus, aliada a práticas de ensino e pesquisa, por alunos de Iniciação
} Científica do Ensino Médio: Relato de experiência

\author{
Perceptions about environmental sustainability during a new Coronavirus pandemic, combined \\ with teaching and research practices, by high school scientific initiation students: Experience
} report

Percepciones sobre la sostenibilidad ambiental durante la pandemia por el nuevo coronavirus, combinado con prácticas de enseñanza e investigación, por estudiantes de iniciación científica de secundaria: Informe de experiência

Recebido: 19/05/2021 | Revisado: 28/05/2021 | Aceito: 31/05/2021 | Publicado: 14/06/2021

Daniel Almeida Ferreira Barbosa

ORCID: https://orcid.org/0000-0002-9557-5637 Universidade Federal do Ceará, Brasil E-mail: danielodontologia@gmail.com

Walter Martins Dantas Neto

ORCID: https://orcid.org/ 0000-0002-3958-6104

Escola de EEFM Félix de Azevedo, Brasil

E-mail: walterdantasneto@gmail.com

Rebeca Moraes Lima

ORCID: https://orcid.org/ 0000-0002-5650-1424

Escola de EEFM Félix de Azevedo, Brasil

E-mail: rebekamoraes@gmail.com

Ana Carolina da Silva Saraiva

ORCID: https://orcid.org/ 0000-0001-9552-3127

Universidade Federal do Ceará, Brasil

E-mail: carolinassaraiva@ hotmail.com

Ana Alicia Sales Ricardo

ORCID: https://orcid.org/0 0000-0001-6614-0936

Universidade Federal do Ceará, Brasil

E-mail: anaaliciasales10@gmail.com

Adília Mirela Cid

ORCID: https://orcid.org/ 0000-0002-0811-5924

Universidade Federal do Ceará, Brasil

E-mail: adiliamirela1@gmail.com

Paulo Goberlânio de Barros da Silva

ORCID: https://orcid.org/ 0000-0002-1513-9027

Centro Universitário Unichristus, Brasil

E-mail: paulo_goberlanio@yahoo.com.br

Lúcio Mitsuo Kurita

ORCID: https://orcid.org/ 0000-0002-9676-4376

Universidade Federal do Ceará, Brasil

E-mail: luciokurita@gmail.com

Fábio Wildson Gurgel Costa

ORCID: https://orcid.org/ 0000-0002-3262-3347

Universidade Federal do Ceará, Brasil

E-mail: fwildson@yahoo.com.br

\begin{abstract}
Resumo
O presente trabalho tem como objetivo fazer o relato de uma experiência com alunos de Iniciação Científica do Ensino Médio, em Fortaleza-CE, sobre sustentabilidade ambiental durante pandemia pelo COVID-19. A primeira etapa fundamentou-se na realização de oficinas temáticas de aprendizagem teórico-práticas com os alunos do ensino médio da escola mencionada, ademais, houve a elaboração de material didático. Os temas abordados pelas oficinas foram: "Sustentabilidade ambiental: qual o meu papel na sociedade"; "Cidadania e sociedade no contexto da Escola e Universidade"; "Gestão e gerenciamento de resíduos sólidos em serviços de saúde"; "Gerenciamento dos resíduos radiológicos em serviços odontológicos”. A segunda etapa consistiu na realização de uma análise situacional sobre
\end{abstract}


conhecimentos e atitudes acerca da temática sustentabilidade ambiental tendo alunos do primeiro ao terceiro ano da escola como público, a Plataforma "Google Forms" foi utilizada como ferramenta. A análise situacional sobre a percepção de alunos do Ensino Médio sobre sustentabilidade ambiental permitiu observar que os escolares apontaram importantes reflexos ocasionados pela pandemia decorrente do novo coronavírus.

Palavras-chave: Educação fundamental e médio; Oficinas de trabalho; Meio ambiente e saúde pública; Radiologia.

\begin{abstract}
The aim of this study is report an experience with high school scientific initiation students, in Fortaleza-CE, about environmental sustainability during a pandemic by COVID-19. The first stage was based on thematic workshops on theoretical and practical learning with high school students from the school mentioned, in addition, there was the development of didactic material. The themes covered by the workshops were: "Environmental sustainability: what is my role in society"; "Citizenship and society in the context of the School and University"; "Management and management of solid waste in health services"; "Management of radiological waste in dental services". The second phase consisted of conducting a situational analysis on knowledge and attitudes about the theme of environmental sustainability with students from the first to the third year of the school as public, the "Google Forms" Platform was used as a tool. The situational analysis on the perception of high school students about environmental sustainability allowed us to observe that the students pointed out important reflexes caused by the pandemic resulting from the new coronavirus.
\end{abstract}

Keywords: Primary and secondary education; Workshops; Environment and public health; Radiology.

\title{
Resumen
}

Este artículo tiene como objetivo reportar una experiencia con estudiantes de iniciación científica de secundaria, en Fortaleza-CE, sobre sostenibilidad ambiental durante una pandemia por COVID-19. La primera etapa se basó en talleres temáticos de aprendizaje teórico y práctico con estudiantes de secundaria de la escuela mencionada, además, se realizó la elaboración de material didáctico. Los temas tratados por los talleres fueron: "Sostenibilidad ambiental: cuál es mi papel en la sociedad"; "Ciudadanía y sociedad en el contexto de la Escuela y la Universidad"; "Manejo y manejo de residuos sólidos en los servicios de salud"; "Gestión de residuos radiológicos en servicios dentales". La segunda etapa consistió en la realización de un análisis situacional sobre conocimientos y actitudes sobre el tema de la sustentabilidad ambiental con alumnos de primer a tercer año de la escuela como público, se utilizó la Plataforma "Google Forms" como herramienta. El análisis situacional sobre la percepción de los estudiantes de secundaria sobre la sostenibilidad ambiental permitió observar que los estudiantes señalaron reflejos importantes provocados por la pandemia resultante del nuevo coronavirus.

Palabras clave: Educación primaria y secundaria; Talleres de trabajo; Medio ambiente y salud pública; Radiología.

\section{Introdução}

É necessário maior reconhecimento acerca da importância da ciência para o desenvolvimento de uma sociedade crítica e em busca de melhorias, seja no campo da saúde, tecnológico ou humano. Nesse contexto, buscando institucionalizar as ações de incentivo e fomento à pesquisa, no Brasil, foi criado o Conselho Nacional de Desenvolvimento Científico e Tecnológico CNPq -, em 1951. A partir de então iniciou o financiamento da atividade do aluno de Iniciação Científica - IC -, através da concessão de bolsas periódicas de fomento à pesquisa para acadêmicos. Durante muito tempo a atividade de IC era realizada prioritariamente em instituições de ensino superior, no entanto, visando estimular alunos de escolas do ensino médio a se inserirem no contexto da universidade, iniciativas para a cobertura dos programas de IC no ambiente escolar foram desenvolvidas. Dessa forma, há um destaque acerca da necessidade de protagonismo estudantil inerente à temas voltados para a sustentabilidade ambiental e sua relação com a sociedade (Barbosa et al., 2020; Massi \& Queiroz, 2010).

O surto causado por uma variação do Corona Vírus (COVID-19) marcou o ano de 2020, gerando, dessa forma, um novo panorama mundial, o que obrigou a população a adotar uma série de novos hábitos, como a adesão da quarentena. Com uma maior quantidade de horas da população em casa, o consumo de energia e de água, além de uma maior produção de resíduos foi consideravelmente ampliado (Oliveira et al., 2020).

Atitudes de extrema relevância, como a adoção de algumas medidas sustentáveis básicas a exemplo de fechar bem as torneiras quando não for mais utilizá-las, diminuir o tempo gasto durante o banho e reduzir a quantidade de água utilizada, tornaram-se ainda mais necessárias, visto que essas iniciativas contribuem para a economia de água, evitando seu desperdício, o que, no cenário atual, é de extrema importância para minimizar os impactos provocados ao meio ambiente (Carvalho et al., 
2020).

Diante de uma sociedade em que o uso de resíduos descartáveis é constante, a adoção de iniciativas que visem um desenvolvimento sustentável torna-se cada vez mais necessária. A adoção de um desenvolvimento sustentável consiste, em síntese, na implantação de medidas a partir de uma lógica em que as necessidades presentes do ser humano sejam satisfeitas sem o comprometimento, portanto, da capacidade de satisfazer as necessidades das gerações futuras (Ross et al., 2012).

O tema acerca de saúde ambiental objetiva identificar os agravos ocasionados ao meio ambiente que possam gerar interferência no bem-estar e na saúde humana, sendo imprescindível a preservação do meio ambiente para que tal saúde seja preservada (Brasil, 2005). Segundo a Organização Mundial da Saúde (OMS), a definição de saúde reporta não apenas a ausência de doenças, mas considera o bem-estar físico, mental e social do ser humano a agentes biológicos, físicos e químicos causadores de condições potencialmente perigosas podem ocasionar efeitos adversos ao meio ambiente e dessa forma afetar a saúde do indivíduo (Segres \& Ferraz, 1997).

Desde a invenção da radiologia, é indiscutível sua importância para o desenvolvimento das ciências (Bampi, Sechi \& Gonçalves, 2013). No entanto, embora haja diversos benefícios acarretados pelos exames imaginológicos, a deposição incorreta do efluentes gerados pela atividade de revelação dos filmes radiográficos tem sido palco para discussão na área. Durante o processamento químico de filmes radiográficos são utilizados efluentes, que são representados pelo líquido revelador, pelo fixador e pela água de lavagem, no entanto tais líquidos necessitam de tratamento adequado antes de seu descarte no meio ambiente (Teschire et al., 2002), visto que consistem em soluções com altas concentrações de prata, hidroquinona, quinona, metol, tiossulfato de sódio, sulfito de sódio e ácido bórico, além de outros químicos altamente tóxicos à saúde ambiental e humana, como cianeto, cloreto, ferro, fósforo total, nitrogênio total e sulfito (Hocervar \& Raya-Rodrigues, 2002).

A conjuntura descrita torna-se dessa forma palco propício para uma forte discussão sobre a problemática dos cuidados necessários com o meio ambiente em tempos de pandemia. Esse assunto, especialmente no ambiente escolar, é de extrema relevância, visto que é um local favorável para a construção de uma visão crítica, gerando no aluno do ensino médio a reflexão acerca dos problemas socioambientais. Massi e Queiroz (2010) reforçam a percepção do aluno acerca da sua inserção em um processo educacional mais aberto do que o desenvolvido pela escola, sendo um importante instrumento para a construção do seu próprio futuro enquanto indivíduo.

Dessa forma, ações interdisciplinares são de considerável relevância para que possam levar até a escola conceitos e práticas de IC relacionadas ao tema de sustentabilidade ambiental, tais como as mediadas pelo programa institucional de bolsas de iniciação científica para o ensino médio (PIBIC-EM) firmado entre a Universidade Federal do Ceará (UFC) e o Conselho Nacional de Desenvolvimento Científico e Tecnológico (CNPq).

Os objetivos deste trabalho foram: 1) Contextualizar alunos do Ensino Médio acerca da temática "sustentabilidade ambiental e gerenciamento de determinados resíduos odontológicos" em tempos de pandemia pelo novo coronavírus; 2) Construção de material didático abordando o correto gerenciamento de resíduos oriundos do processamento químico de radiografias odontológicas, bem como infográficos correlacionando COVID-19 e sustentabilidade; 3) Realização de uma análise situacional, através de um questionário, sobre conhecimentos e atitudes de escolares do Ensino Médio acerca da temática "sustentabilidade ambiental" e o impacto sobre esta decorrente do novo coronavírus.

\section{Metodologia}

\section{Contexto de aplicação e seleção dos alunos bolsistas}

Esta pesquisa trata-se de um estudo observacional, quantitativo, transversal e descritivo realizado por meio de um formulário eletrônico (Estrela, 2018). Os alunos foram selecionados pela diretora da escola que utilizou de critérios como o 
perfil e desempenho dos alunos, bem como àqueles que atendessem aos requisitos constantes no Edital Pibic-EM 2020. A escola vinculada ao projeto trata-se da Escola Estadual de Ensino Fundamental e Médio Félix de Azevedo, situada no Bairro Rodolfo Teófilo. A Figura 1 evidencia sua localização baseada no Google maps, na qual podemos observar a distância até a Faculdade de Farmácia, Odontologia e Enfermagem da Universidade Federal do Ceará está o Curso de Odontologia. Tal distância se tornou importante ferramenta estratégica no desenvolvimento das atividades do projeto.

Ademais, segundo os últimos dados (2019) divulgados pelo Instituto Nacional de Estudos e Pesquisas Educacionais Anísio Teixeira (INEP), a escola apresentou indicador de nível socioeconômico médio-baixo, média de 40,8 alunos por turma, percentual médio de docentes com nível superior acima de $93 \%$ e taxa média de reprovação muito baixa (cerca de $1 \%$ ).

Figura 1. Localização geográfica da EEFM Félix de Azevedo em relação ao curso de Odontologia da UFC e o CEO Rodolfo Teófilo.

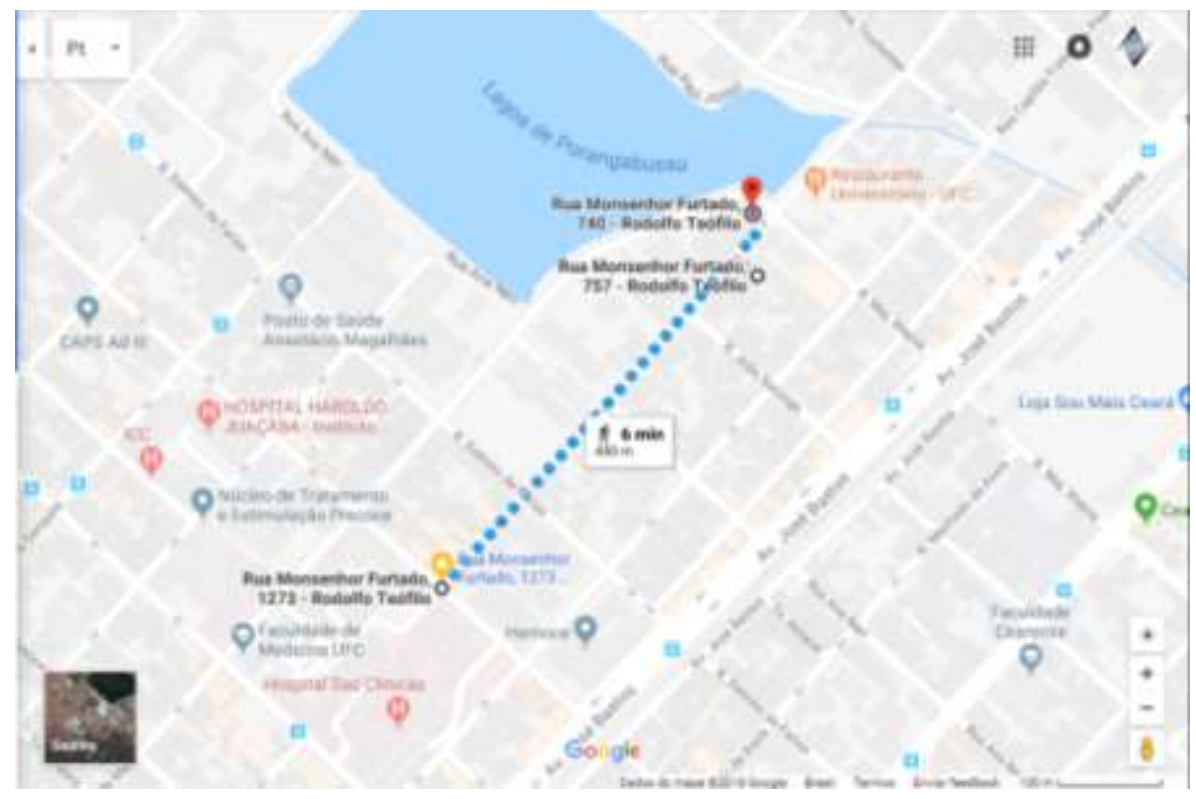

Fonte: Google maps.

\section{Oficinas temáticas teórico-práticas}

Diante da necessidade de fornecer ao bolsista PIBIC-EM um ensino de áreas correlatas, em que houvesse a integração entre as áreas pedagógicas e o estímulo à uma busca ativa do conhecimento, tendo em vista uma maior autonomia do bolsista para variados contextos, foram realizadas oficinas temáticas, através de seminários, baseados em uma metodologia ativa, na qual o aluno torna-se o principal agente responsável pela aprendizagem.

Durante a realização dos seminários temáticos, houve a presença dos participantes do projeto de forma integral, sendo eles o professor orientador, os alunos de pós-graduação e os alunos do PIBIC do curso de Odontologia da Faculdade de Farmácia, Odontologia e Enfermagem (FFOE), proporcionando, desse modo, um debate construtivo acerca dos temas.

As oficinas temáticas foram realizadas através de encontros presenciais nas dependências do curso de Odontologia da FFOE-UFC. Diante da implantação do isolamento social a partir de março de 2020, as reuniões para apresentação das oficinas também ocorreram de forma virtual através da plataforma "Google Meet".

\section{Elaboração de material didático sobre educação ambiental}

Para dar subsídio às oficinas temáticas, os alunos do ensino médio foram estimulados a construírem um material didático direcionado às práticas ambientalmente adequadas em se tratando do gerenciamento de resíduos químicos, as quais 
deveriam ser pautadas na educação ambiental já que esta oferece aos indivíduos a tomada de consciência da interdependência econômica, social, política e ecológica nos diversos setores da sociedade (Dias, 1993).

Durante a realização das oficinas teórico-práticas de aprendizagem, os alunos da escola foram instigados a pensar em como contextualizar os saberes acumulados em material de divulgação, impressos e digitais. Nesta fase, além de material didático sobre educação ambiental divulgado entre todos os alunos da escola, também foi dado destaque para o gerenciamento de resíduos químicos, muito embora todos os resíduos demandem especial atenção.

Foi realizado, portanto, a elaboração de folders, cartazes, os quais serviram, também, como material de apoio para a realização da segunda etapa deste projeto, que incluiu a realização de aplicação de questionário com os alunos da EEFM Félix de Azevedo.

\section{Avaliação de conhecimentos e atitudes sobre educação ambiental, sustentabilidade e COVID-19 e gerenciamento de resíduos}

Os alunos do ensino médio selecionados, após terem adquirido conhecimento com a etapa de oficinas temáticas e construção de material didático, participaram de uma pesquisa cujo objetivo principal foi avaliar o conhecimento e atitudes sobre sustentabilidade ambiental, correlacionando sustentabilidade e COVID-19.

Para tanto, inicialmente foi realizado um estudo avaliativo, de natureza quantitativa e qualitativa. Desta forma, a pesquisa avaliativa esteve sujeita a um procedimento científico que permitisse analisar e compreender as relações de causalidade entre os diferentes componentes de intervenção conforme descrito por Denis et al., 2011. Os participantes desse estudo foram selecionados por amostragem intencional, em que foram convidados a participar alunos do primeiro ao terceiro ano da Escola Félix de Azevedo.

Ademais, foram respeitados os preceitos éticos em pesquisa, e o referido projeto foi submetido ao Comitê de Ética em Pesquisa com seres humanos da UFC através da Plataforma Brasil e aprovado com o número 3.931.808. Os voluntários participaram da pesquisa após lerem, concordarem e assinarem o Termo de Consentimento Livre e Esclarecido, sendo assegurado sigilo quanto à sua identidade e informações prestadas, e, quando menor de idade, concordarem e assinarem o Termo de Assentimento Livre e Esclarecido, sendo o Termo de Consentimento Livre e Esclarecido assinado pelo responsável.

A etapa quantitativa se apresentou como um estudo transversal observacional, no qual foi utilizado um questionário estruturado aplicado pelo bolsista PIBIC-EM, através da plataforma digital "Google Forms", devido à pandemia do Corona vírus, sob a supervisão direta do professor proponente do presente projeto. As perguntas constantes nesse instrumento foram construídas durante as oficinas temáticas e tiveram o protagonismo do aluno bolsista, sugerindo tópicos e discutindo com o coordenador e demais participantes (alunos de pós-graduação e os de iniciação científica) as melhores abordagens a serem escolhidas quando da construção do roteiro de entrevista.

De forma introdutória, os alunos do PIBIC EM foram apresentados à plataforma "Google Forms", uma vez que durante o período de quarentena pela pandemia do vírus Covid-19 a aplicabilidade presencial do questionário tornou-se inviável. Foi realizada uma oficina online, abordando as ferramentas necessárias para a produção desse formulário online (Figura 2). 
Figura 2. Aparência visual do cabeçalho do formulário aplicado aos alunos.

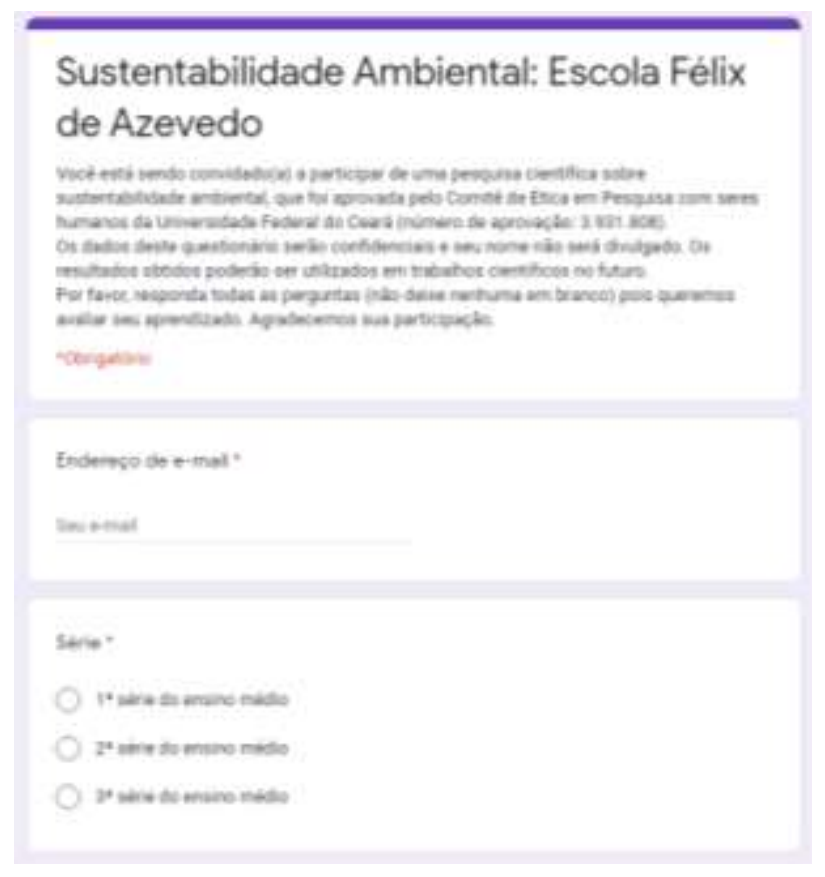

Fonte: Autores.

\section{Análise dos dados}

As oficinas temáticas e a etapa de elaboração de material didático foram analisadas de forma subjetiva, sendo observado o rendimento dos alunos durante as atividades.

Os dados foram tabulados no Microsoft Excel e exportados para o software Statistical packcage for the Social Sciences (SPSS) versão 20,0 para Windows no qual foram expressas as frequências absoluta e percentual cruzadas com os períodos por meio dos testes exato de Fisher ou qui-quadrado de Pearson adotando uma confiança de $95 \%$.

\section{Resultados e Discussão}

\section{Oficinas do covid}

Diante do atual cenário de pandemia, as atividades presenciais necessitaram ser interrompidas, mas visando não perder as atividades de ensino teórico-práticas, foram realizados encontros semanais com a presença dos alunos bolsistas PIBIC-EM, juntamente com o professor proponente e os alunos da graduação.

Os encontros foram realizados através da plataforma "Google meet", em que houve inicialmente uma leitura prévia de reportagens e matérias acerca da pandemia do novo Coronavirus e, durante a reunião, uma discussão baseada no que foi coletado. O senso crítico dos alunos bolsistas foi constantemente explorado.

O primeiro tema a ser debatido durante as oficinas foi "Quais possíveis efeitos do coronavírus no ambiente”, em que, foram apresentados os impactos, negativos e positivos, no meio ambiente decorrentes da nova rotina implantada, sobretudo a adoção da quarentena. Os efeitos positivos se sobressaíram durante a discussão, principalmente acerca da redução da emissão dos gases atmosféricos

O tema "Coronavírus e acúmulo de lixo caseiro e hospitalar" também foi abordado, sendo de extrema relevância, sobretudo no que tange ao descarte adequado do lixo hospitalar, a incineração, o qual foi tratado como um tema inovador para os alunos do PIBIC-EM. Dando continuidade a sequência de matérias e artigos, também foram debatidos os temas correlacionando o novo Coronavírus com degradação ambiental, sua repercussão na agricultura e na criação de animais.

Após a discussão dos temas, foi proposto aos alunos bolsistas PIBIC-EM a apresentação dos temas através da 
elaboração e apresentação de seminários.

Figura 3. Slide elaborado pela bolsista para a apresentação do tema.

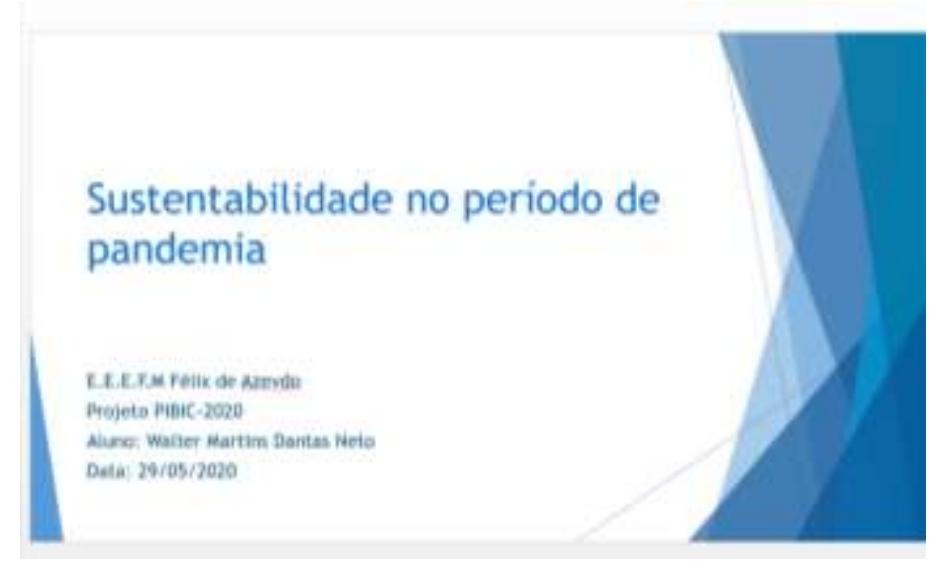

Fonte: Autores.

\section{Oficinas teórico-práticas de aprendizagem}

Durante o período pré-pandemia, o espaço da Clinica de Radiologia da Faculdade de Farmácia, Odontologia e Enfermagem serviu de palco para a realização de encontros periódicos, com a frequência de 7 dias. As oficinas temáticas teórico-práticas contaram com a participação do professor orientador, dos alunos de pós-graduação e dos alunos do PIBIC do curso de Odontologia da Faculdade de Farmácia, Odontologia e Enfermagem (FFOE)

O tema sustentabilidade ambiental e gerenciamento de resíduos produzidos na clínica odontológica foi amplamente abordado e discutido durante as oficinas temáticas, visto que o principal objetivo das reuniões semanais era a aprendizagem significativa dos alunos bolsistas acerca do assunto, através da adoção de metodologia ativa. Durante os primeiros 4 meses do projeto foram realizadas oficinas temáticas onde os seguintes temas foram apresentados e debatidos:

"Sustentabilidade ambiental: qual o meu papel na sociedade?". Nessa oficina temática, os alunos apresentaram suas percepções acerca da correlação dos conceitos de sustentabilidade ambiental e de atuação deles na sociedade como cidadãos. Durante as apresentações, foi realizada uma discussão sobre como as atitudes individuais podem interferir no equilíbrio ambiental, além de dialogar sobre iniciativas pessoais que podem favorecer a preservação ambiental, sendo tais discussões realizadas por meio de exposição descritiva de slides. Ao final do encontro, observou-se que muitas ideias foram abordadas e o conhecimento dos alunos acerca do papel deles na sociedade foi ressaltado e esclarecido. Além disso, foram realizadas as correções necessárias, acerca do conteúdo e da formatação do trabalho, para melhorar a apresentação produzida (Figura 4a).

"Cidadania e sociedade no contexto da Escola e Universidade". Para discutirmos tal tema, foi pedido para que os bolsistas produzissem uma breve aula explicativa sobre o assunto, por meio de uma apresentação de slides (Figura 4b). Ao final das explanações, os mentores realizaram as devidas considerações e correções acerca da apresentação e da abordagem do tema, tendo em vista melhorar a qualidade da aula e do conteúdo abordando, dando um maior suporte para a produção de materiais futuros.

"Gestão e gerenciamento de resíduos sólidos em serviços de saúde". Nessa oficina, houve uma apresentação por meio de slides sobre a forma correta da gestão e do gerenciamento de resíduos sólidos nos serviços de saúde (Figura 4c). Foram utilizadas imagens ilustrativas demonstrando como ocorre esses procedimentos dos resíduos produzidos, usando de exemplo também a Clínica Odontológica da UFC. Após a exposição foi aberto um momento para retirada de dúvidas e troca de ideias, no qual os bolsistas puderam conhecer melhor sobre o Plano de gestão de resíduos sólidos, qual sua importância e como ele é elaborado. 
"Gerenciamento dos resíduos radiológicos em serviços odontológicos". Nesse tema, também foi solicitado aos bolsistas que produzissem uma aula expositiva do assunto, utilizando slides (Figura 4d). Nesse tópico, o conhecimento prévio dos alunos, adquirido pela participação do Pibic- EM, sobre o processamento de filmes radiográficos foi de extrema importância, uma vez que facilitou a produção do material e o andamento da apresentação. Ao final desse encontro, também foram realizadas as devidas correções e consideração acerca da desenvoltura dos bolsistas.

Figura 4a - 4d. 4a. Realização das correções. 4b Slides elaborados pela bolsista para a apresentação do tema. 4c Slides elaborados pela bolsista para a apresentação do tema. 4d Apresentação da bolsista sobre o tema.

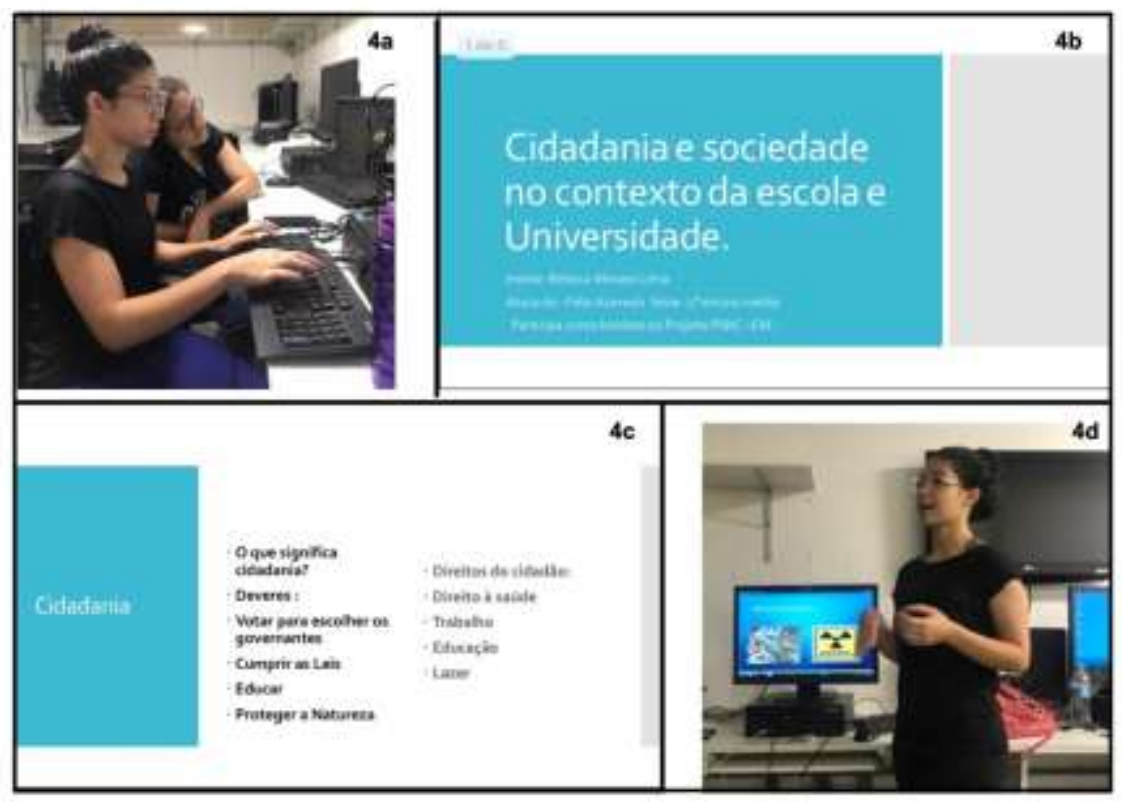

Fonte: Autores.

Construção de um novo material didático sobre o gerenciamento de resíduos oriundos do processamento químico de radiografias odontológicas

Como forma de subsídio às oficinas temáticas, os alunos do ensino médio foram estimulados a construir um material didático direcionado às práticas ambientai, no âmbito do correto gerenciamento de resíduos oriundos do processamento químico de radiografias. Durante a realização das oficinas -práticas de aprendizagem, os bolsistas foram desafiados a sintetizar seus conhecimentos adquiridos na confecção de um material de divulgação de informações. Nessa etapa, foi ressaltada a importância dos três 3R`s (reciclagem, redução e reutilização), de modo a evidenciar as consequências do incorreto descarte e manuseio dos resíduos radiológicos. Em conjunto, com o Professor Coordenador, alunos do PIBIC e alunos da pós-graduação, os alunos do PIBIC EM realizaram uma oficina para confecção de um folder para disseminação da adequada sistemática de descarte de tais resíduos, levando em consideração os saberes já abordados em outras oficinas acerca do impacto ambiental que tais materiais podem ter no meio ambiente (Figura 5). 
Figura 5. Folder produzido pelos alunos bolsistas.

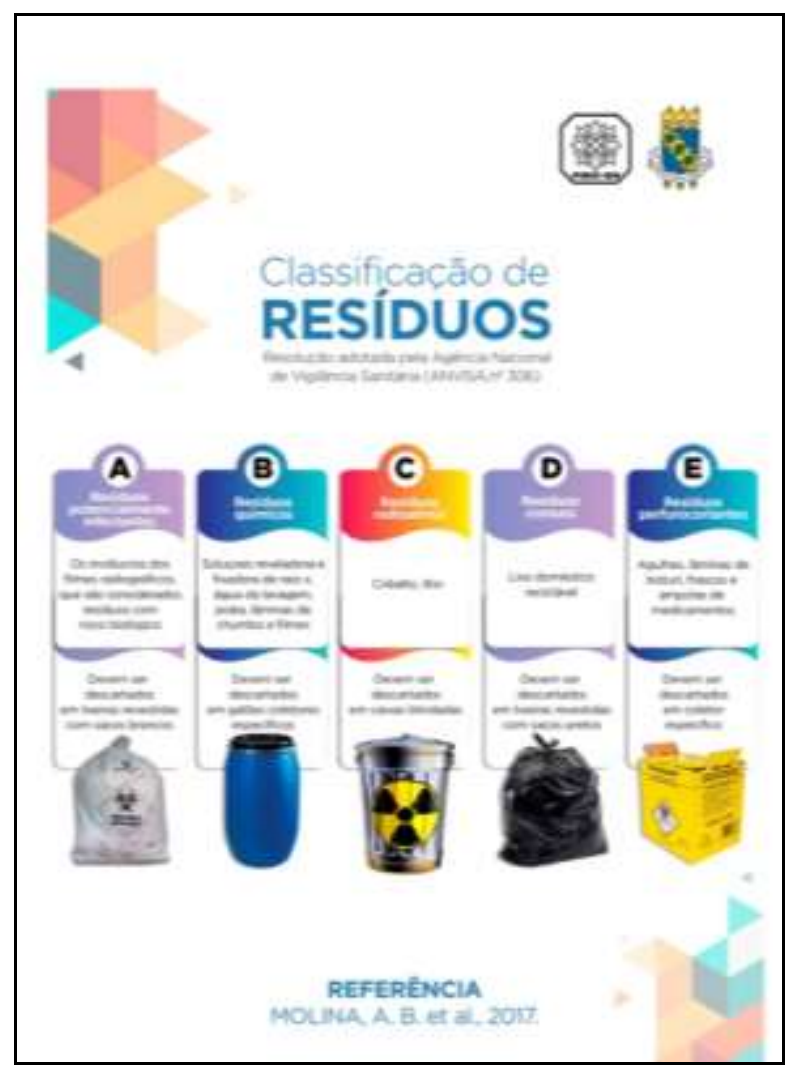

Fonte: Autores.

Além das atividades presenciais e online, de modo remoto, os estudantes produziram artes visuais informativas acerca dos assuntos abordados no projeto, tendo como objetivo a divulgação da atuação dos discentes e de informações relevantes. Desse modo, foi realizada a publicação de postagens informativas, construídas durante as oficinas temáticas, nas redes sociais da Escola Félix de Azevedo (Figura 6). Assim, pode-se proporcionar uma maior divulgação e ampliação da atuação dos bolsistas no presente projeto, além da democratização das informações relevantes abordadas durante esse período. Ademais, ressalta-se que esse projeto é de grande importância para o Programa de Pós-Graduação, único com conceito 5 em Odontologia na região Nordeste Norte, em virtude da necessidade de se realizarem atividades voltadas à Educação no Ensino Médio.

Figura 6. Print da tela da rede social da Escola.

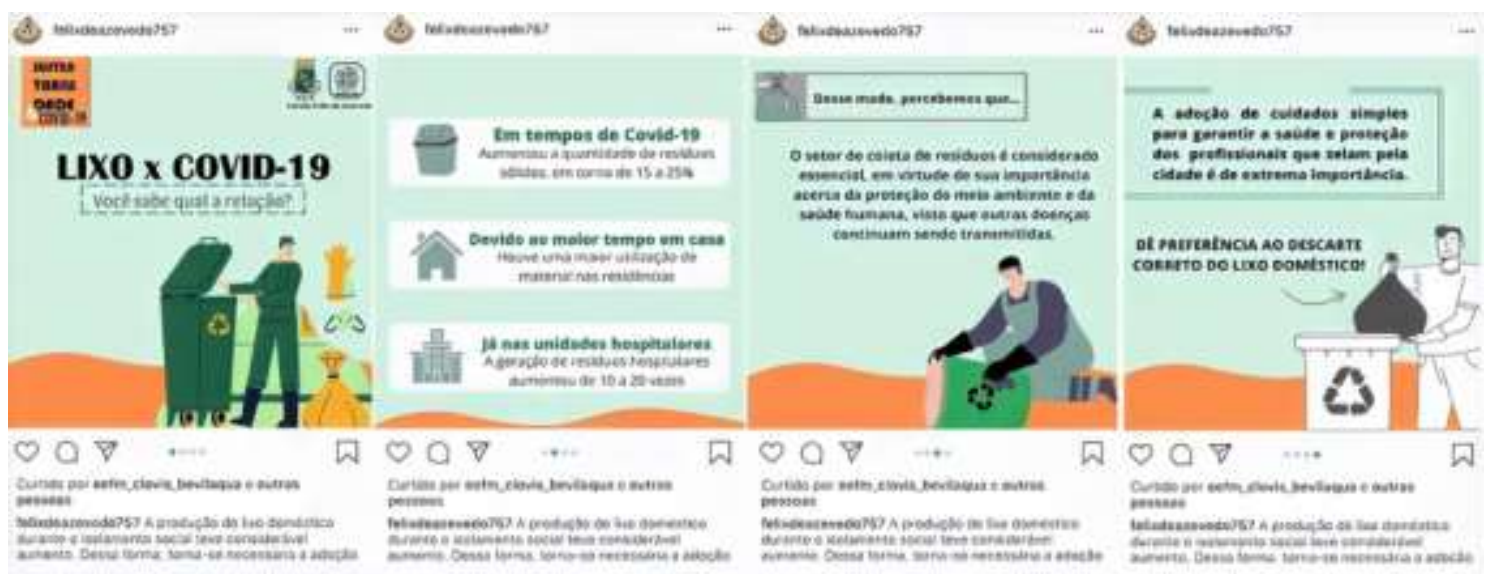

Fonte: Autores. 
Análise situacional sobre conhecimentos e atitudes acerca da temática "sustentabilidade ambiental" com os alunos do primeiro ao terceiro ano da Escola

A amostra foi composta por 64 estudantes do ensino médio dos quais $6(9.4 \%)$ eram da primeira série, $28(43.7 \%)$ da segunda série e $30(46.9 \%)$ da terceira série. A maior parte dos estudantes tinha menos de 18 anos $(45,70,3 \%)$ e eram do sexo feminino $(36,56,3 \%)$ sem diferença entre os períodos (Tabela 1$)$.

Das medidas utilizadas para proteger o meio ambiente, a economia de água $(45,70,3 \%)$ e de energia $(44,68,8 \%)$ foram as mais usadas, mas apenas $16(25,0 \%)$ participantes referiram separação do lixo descartável, nenhum referiu utilização de produtos ecológicos e três $(4,7 \%)$ citaram não tomar nenhuma medida. Não houve diferença entre os períodos (Tabela 1$)$.

Tabela 1. Medidas de proteção ao meio ambiente.

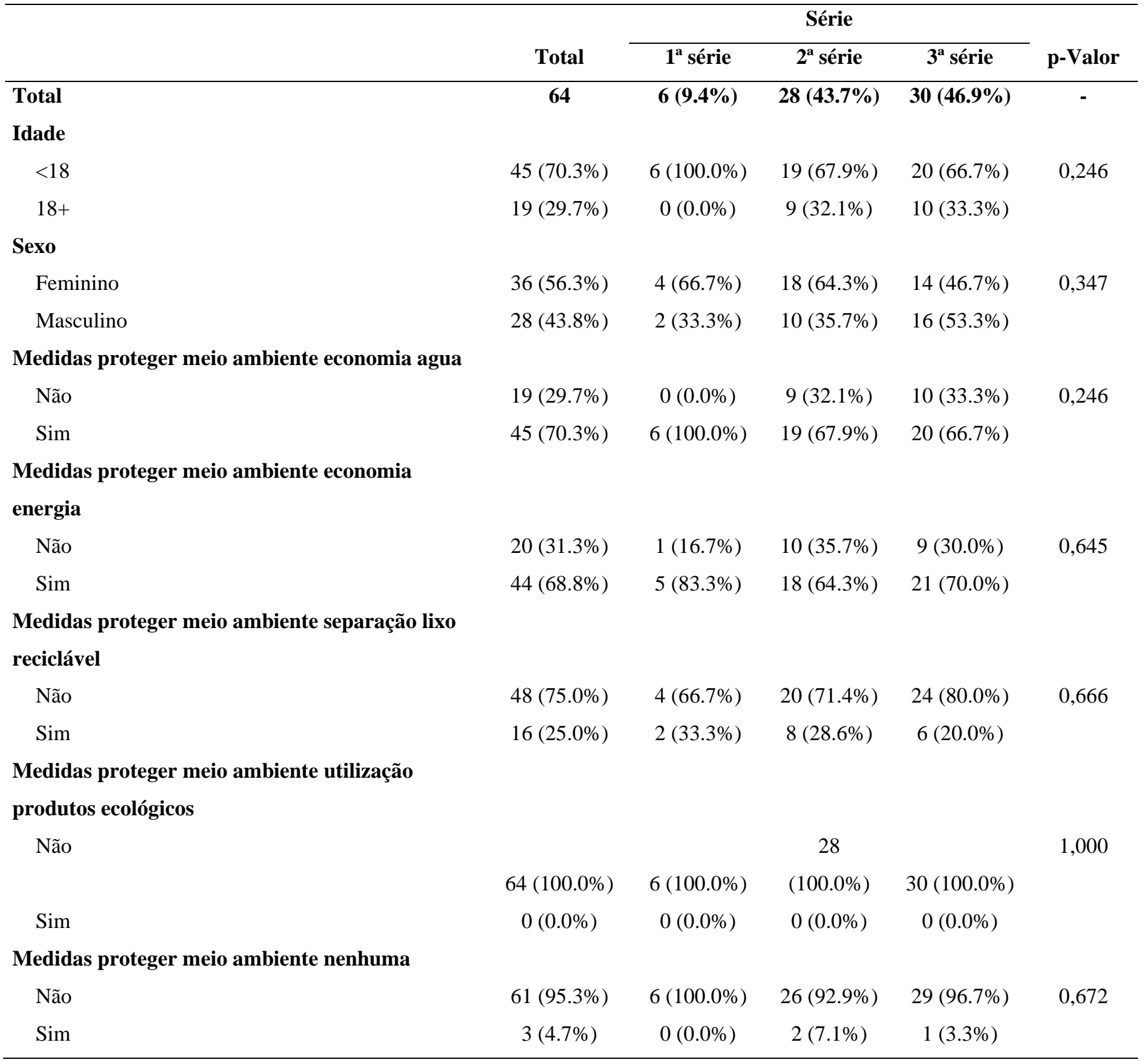


A maior parte dos estudantes citou que costuma separar o lixo comum de outros lixos tais como pilhas, baterias, eletrodomésticos e óleo de cozinha apenas às vezes $(24,37.5 \%)$ e que nesse momento de isolamento social o seu interesse por assuntos relacionados ao meio ambiente é apenas razoável (32, 50,0\%). A maior parte também acredita que durante a pandemia houve diminuição poluição rios lagoas $(41,64,1 \%)$ e do desmatamento $(35,54,5)$, enquanto $50,0 \%(\mathrm{n}=32)$ acredita que houve diminuição da emissão gases e apenas 14 (21,9\%) que a pandemia ajudou aumentou produção campo. Não houve diferença entre os períodos (Tabela 2).

Tabela 2. Impactos da pandemia ao meio ambiente.

\begin{tabular}{|c|c|c|c|c|c|}
\hline & \multirow[b]{2}{*}{ Total } & \multicolumn{3}{|c|}{ Série } & \multirow{2}{*}{$\begin{array}{c}\text { p- } \\
\text { Valor }\end{array}$} \\
\hline & & $\mathbf{1}^{\mathrm{a}}$ série & $2^{a}$ série & $3^{a}$ série & \\
\hline \multicolumn{6}{|c|}{$\begin{array}{l}\text { Você costuma separar o lixo comum de outros lixos tais } \\
\text { como pilhas, baterias, eletrodomésticos, óleo de cozinha, } \\
\text { entre outros? }\end{array}$} \\
\hline Nunca & $14(21.9 \%)$ & $3(50.0 \%)$ & $8(28.6 \%)$ & $3(10.0 \%)$ & 0,566 \\
\hline Raramente & $16(25.0 \%)$ & $1(16.7 \%)$ & $7(25.0 \%)$ & $8(26.7 \%)$ & \\
\hline Às vezes & $24(37.5 \%)$ & $2(33.3 \%)$ & $9(32.1 \%)$ & $13(43.3 \%)$ & \\
\hline Muitas vezes & $5(7.8 \%)$ & $0(0.0 \%)$ & $2(7.1 \%)$ & $3(10.0 \%)$ & \\
\hline Sempre & $5(7.8 \%)$ & $0(0.0 \%)$ & $2(7.1 \%)$ & $3(10.0 \%)$ & \\
\hline \multicolumn{6}{|c|}{$\begin{array}{l}\text { Nesse momento de isolamento social, qual o seu interesse } \\
\text { por assuntos relacionados ao meio ambiente? }\end{array}$} \\
\hline Nenhum interesse & $1(1.6 \%)$ & $0(0.0 \%)$ & $1(3.6 \%)$ & $0(0.0 \%)$ & 0,250 \\
\hline Pouco interessado & $18(28.1 \%)$ & $4(66.7 \%)$ & $5(17.9 \%)$ & $9(30.0 \%)$ & \\
\hline Razoavelmente interessado & $32(50.0 \%)$ & $1(16.7 \%)$ & $17(60.7 \%)$ & $14(46.7 \%)$ & \\
\hline Muito interessado & $13(20.3 \%)$ & $1(16.7 \%)$ & $5(17.9 \%)$ & $7(23.3 \%)$ & \\
\hline \multicolumn{6}{|c|}{ Pandemia ajudou diminuição emissão gases } \\
\hline Não & $32(50.0 \%)$ & $4(66.7 \%)$ & $16(57.1 \%)$ & $12(40.0 \%)$ & 0,296 \\
\hline Sim & $32(50.0 \%)$ & $2(33.3 \%)$ & $12(42.9 \%)$ & $18(60.0 \%)$ & \\
\hline \multicolumn{6}{|c|}{ Pandemia ajudou diminuição poluição rios lagoas } \\
\hline Não & $23(35.9 \%)$ & $1(16.7 \%)$ & $10(35.7 \%)$ & $12(40.0 \%)$ & 0,553 \\
\hline Sim & $41(64.1 \%)$ & $5(83.3 \%)$ & $18(64.3 \%)$ & $18(60.0 \%)$ & \\
\hline \multicolumn{6}{|c|}{ Pandemia ajudou aumentou produção campo } \\
\hline Não & $50(78.1 \%)$ & $4(66.7 \%)$ & $20(71.4 \%)$ & $26(86.7 \%)$ & 0,290 \\
\hline Sim & $14(21.9 \%)$ & $2(33.3 \%)$ & $8(28.6 \%)$ & $4(13.3 \%)$ & \\
\hline \multicolumn{6}{|c|}{ Pandemia ajudou diminuição desmatamento } \\
\hline Não & $29(45.3 \%)$ & $4(66.7 \%)$ & $9(32.1 \%)$ & $16(53.3 \%)$ & 0,146 \\
\hline Sim & $35(54.7 \%)$ & $2(33.3 \%)$ & $19(67.9 \%)$ & $14(46.7 \%)$ & \\
\hline
\end{tabular}


Durante a pandemia as medidas mais citadas para prevenção de contaminação com COVID-19 foram manter rotina higiene pessoal $(52,81,3 \%)$, seguido de desinfetar compras $(46,71,9 \%)$, de limpar objetos álcool 70 (43, 67,2\%) e não compartilhar objetos uso pessoal (37, 57,8\%). Menos da metade dos estudantes acha que o período de isolamento social pode interferir negativamente no meio ambiente $(41,64,1 \%)$ bem como acreditam que por meio de aumentar a produção de CO2 devido a queima de lixo hospitalar $(26,40,6 \%)$. A maior parte dos estantes acredita que durante a pandemia houve aumento da produção de lixo doméstico $(49,76,6 \%)$ e do consumo de energia (36, 56,3\%). Os estudantes do segundo e terceiro ano acreditam significantemente mais que durante a pandemia houve aumento da produção de lixo doméstico (p=0,031) e que o CO2 não aumentou devido a queima de lixo hospitalar $(\mathrm{p}=0,008)$ (Tabela 3).

Tabela 3. Medidas de prevenção ao COVID-19.

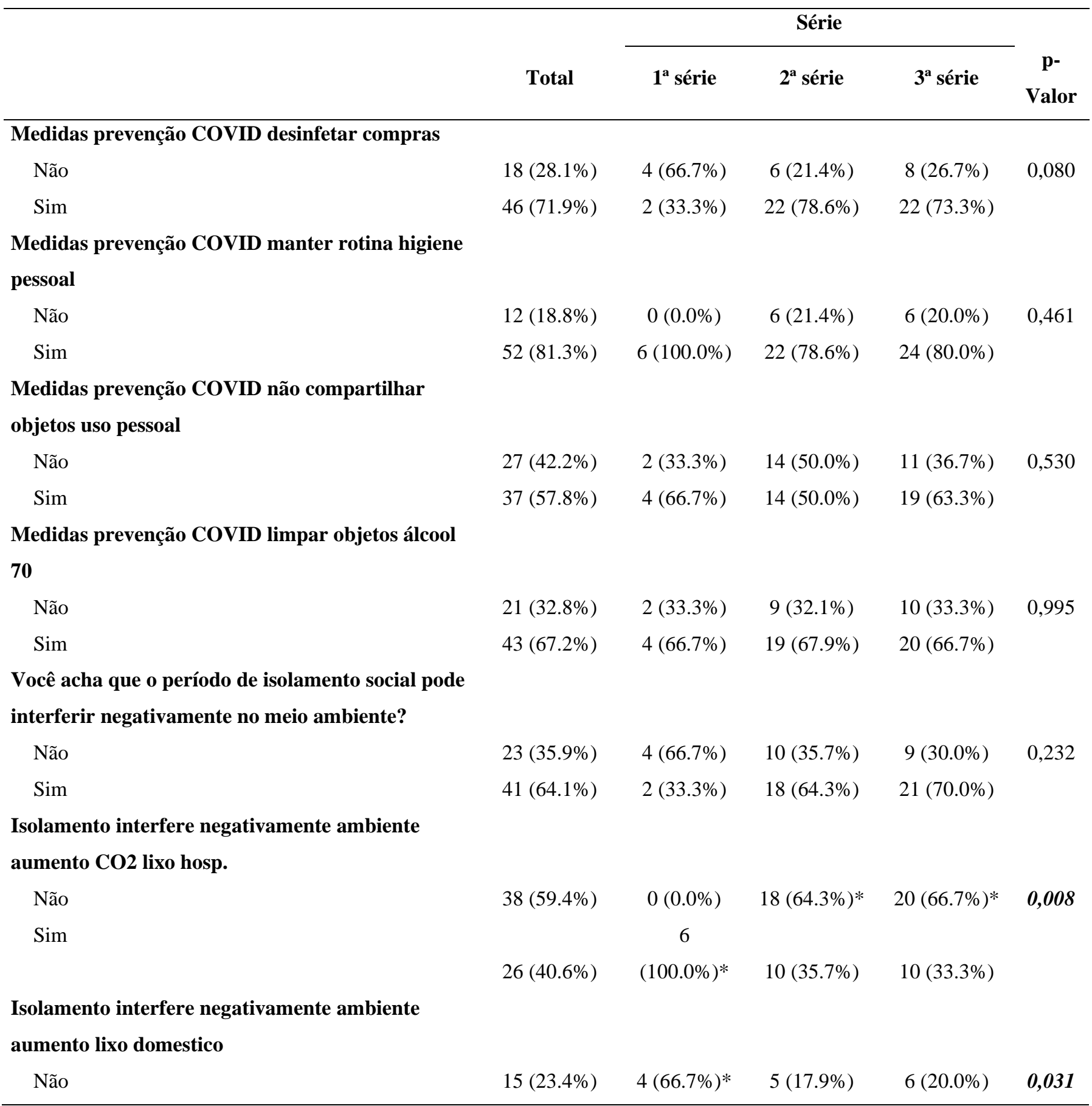




$\begin{array}{lllll}\operatorname{Sim} & 49(76.6 \%) & 2(33.3 \%) & 23(82.1 \%)^{*} & 24(80.0 \%)^{*}\end{array}$

Isolamento interfere negativamente ambiente aumento consumo energia

\begin{tabular}{|c|c|c|c|c|}
\hline Não & $28(43.8 \%)$ & $1(16.7 \%)$ & $12(42.9 \%)$ & $15(50.0 \%)$ \\
\hline Sim & $36(56.3 \%)$ & $5(83.3 \%)$ & $16(57.1 \%)$ & $15(50.0 \%)$ \\
\hline
\end{tabular}

${ }^{*} \mathrm{p}<0,05$, teste exato de Fisher ou qui-quadrado de Pearson (n, \%). Fonte: Autores.

Educação ambiental é um tema abordado na escola foi mencionado por três quartos dos estudantes $(48,75,0 \%)$ e para a maioria destes, meio ambiente é Seres vivos (plantas, animais e seres humanos) e recursos que a natureza oferece (ar, água, solo e alimentos) (44, 68,8\%). Além disso, a maioria toma atitudes como não gastar muita energia (45, 70,3\%) e não contaminar solo $(44,68,8 \%)$ como forma de cuidar do meio ambiente e apenas cinco $(7,8 \%)$ referem não agredir o meio ambiente e dois $(3,1 \%)$ não gastar muita água. Não houve diferença entre os períodos (Tabela 4 ).

Tabela 4. Conhecimento sobre meio ambiente.

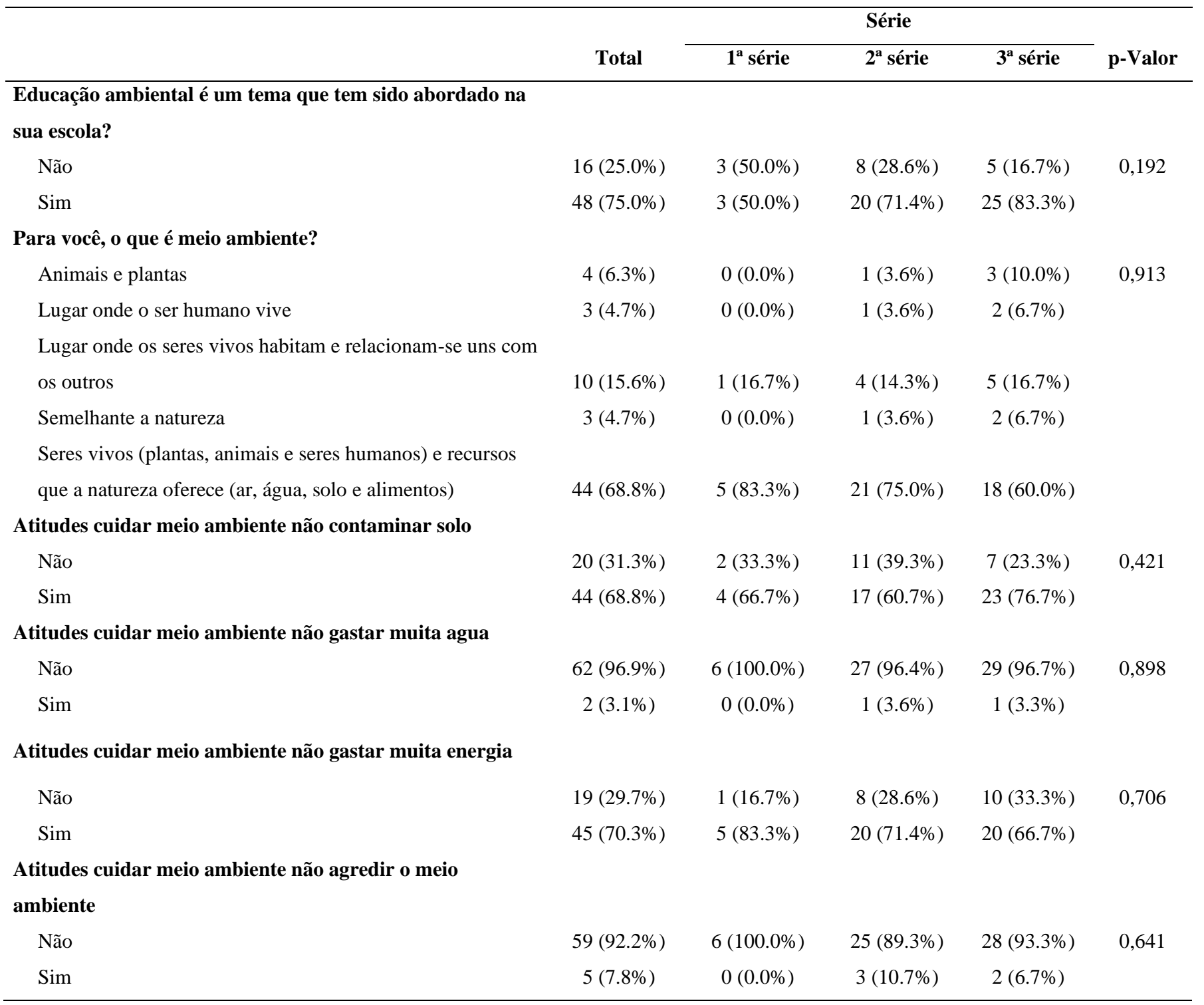


Ao sair do banheiro ou do quarto a maioria cita apagar a luz $(55,85,9 \%)$, porém também não sabe o que ocorre com a água após sua utilização $(26,40,6 \%)$, sendo a maioria significante destes da primeira série do ensino médio (p=0,011). A maior parte dos estudantes também sabe o que significa a expressão “desenvolvimento sustentável” (42, 65,6\%), sendo que nenhum estudante da primeira série refere esse conhecimento $(\mathrm{p}=0,001)$. A maioria também sabe o que é coleta seletiva de resíduos sólidos $(46,71,9 \%)$ com concentração desse nível de conhecimento dos estudantes da segunda e terceira séries (p=0,037) e a maioria dos estudantes acredita que o que diferencia o lixo da poluição é que a poluição é causada por indústrias, carros e máquinas e lixo é produzido pelo ser humano $(28,43,8 \%)$ ou que a poluição é lixo colocado na natureza e lixo é qualquer tipo de resíduo $(23,35,9 \%)$, sem diferença entre as séries do ensino médio (Tabela 5).

Tabela 5. Atitudes de proteção ao meio ambiente.

\begin{tabular}{|c|c|c|c|c|c|}
\hline & \multirow[b]{2}{*}{ Total } & \multicolumn{3}{|c|}{ Série } & \multirow[b]{2}{*}{$\begin{array}{c}\text { p- } \\
\text { Valor }\end{array}$} \\
\hline & & $\mathbf{1}^{\mathrm{a}}$ série & $2^{\mathrm{a}}$ série & $3^{\mathrm{a}}$ série & \\
\hline \multicolumn{6}{|l|}{ Ao sair do banheiro ou do quarto você costuma apagar a } \\
\hline \multicolumn{6}{|l|}{ luz? } \\
\hline Não & $3(4.7 \%)$ & $1(16.7 \%)$ & $1(3.6 \%)$ & $1(3.3 \%)$ & 0,616 \\
\hline Às vezes & $6(9.4 \%)$ & $0(0.0 \%)$ & $3(10.7 \%)$ & $3(10.0 \%)$ & \\
\hline Sim & $55(85.9 \%)$ & $5(83.3 \%)$ & $24(85.7 \%)$ & $26(86.7 \%)$ & \\
\hline \multicolumn{6}{|l|}{ O que ocorre com a água após sua utilização? } \\
\hline Não sei & $26(40.6 \%)$ & $5(83.3 \%)^{*}$ & $12(42.9 \%)$ & $9(30.0 \%)$ & 0,011 \\
\hline É despejada na rua, a céu aberto & $1(1.6 \%)$ & $0(0.0 \%)$ & $1(3.6 \%)$ & $0(0.0 \%)$ & \\
\hline É reaproveitada para o uso & $7(10.9 \%)$ & $0(0.0 \%)$ & $4(14.3 \%)$ & $3(10.0 \%)$ & \\
\hline Penetra no solo & $1(1.6 \%)$ & $1(16.7 \%)$ & $0(0.0 \%)$ & $0(0.0 \%)$ & \\
\hline Vai para estação de tratamento & $21(32.8 \%)$ & $0(0.0 \%)$ & $10(35.7 \%)^{*}$ & $11(36.7 \%)^{*}$ & \\
\hline Vai para os rios & $8(12.5 \%)$ & $0(0.0 \%)$ & $1(3.6 \%)$ & $7(23.3 \%)$ & \\
\hline \multicolumn{6}{|l|}{$\begin{array}{l}\text { Você sabe o que significa a expressão "desenvolvimento } \\
\text { sustentável"? }\end{array}$} \\
\hline Não & $22(34.4 \%)$ & $6(100.0 \%)^{*}$ & $10(35.7 \%)$ & $6(20.0 \%)$ & 0,001 \\
\hline Sim & $42(65.6 \%)$ & $0(0.0 \%)$ & $18(64.3 \%)^{*}$ & $24(80.0 \%)^{*}$ & \\
\hline \multicolumn{6}{|l|}{ Você sabe o que é coleta seletiva de resíduos sólidos? } \\
\hline Não & $18(28.1 \%)$ & $4(66.7 \%)^{*}$ & $9(32.1 \%)$ & $5(16.7 \%)$ & 0,037 \\
\hline Sim & $46(71.9 \%)$ & $2(33.3 \%)$ & $19(67.9 \%)^{*}$ & $25(83.3 \%)^{*}$ & \\
\hline \multicolumn{6}{|l|}{ O que diferencia o lixo da poluição? } \\
\hline Lixo é reaproveitável e poluição não & $4(6.3 \%)$ & $0(0.0 \%)$ & $0(0.0 \%)$ & $4(13.3 \%)$ & 0,086 \\
\hline $\begin{array}{l}\text { Poluição é causada por indústrias, carros e máquinas e lixo é } \\
\text { produzido pelo ser humano }\end{array}$ & $28(43.8 \%)$ & $6(100.0 \%)$ & $13(46.4 \%)$ & $9(30.0 \%)$ & \\
\hline $\begin{array}{l}\text { Poluição é lixo colocado na natureza e lixo é qualquer tipo de } \\
\text { resíduo }\end{array}$ & $23(35.9 \%)$ & $0(0.0 \%)$ & $11(39.3 \%)$ & $12(40.0 \%)$ & \\
\hline Poluição existe na natureza e lixo existe em casa & $3(4.7 \%)$ & $0(0.0 \%)$ & $1(3.6 \%)$ & $2(6.7 \%)$ & \\
\hline Nenhuma das alternativas acima & $6(9.4 \%)$ & $0(0.0 \%)$ & $3(10.7 \%)$ & $3(10.0 \%)$ & \\
\hline
\end{tabular}

*p $<0,05$, teste exato de Fisher ou qui-quadrado de Pearson (n, \%). Fonte: Autores. 
O ano de 2020 será sempre lembrado por um surto causado por uma variação do Corona Vírus (COVID-19). O primeiro caso reportado foi em dezembro de 2019 na cidade de Wuhan, na China. O crescimento acelerado do número de doentes caracterizou a infecção como um surto e, no final de janeiro de 2020, a Organização Mundial de Saúde (OMS) declarou a situação como uma emergência em saúde pública de interesse internacional (Oliveira et al., 2020). Diante do novo panorama mundial, a adoção de novos hábitos tornou-se necessária. A maior parte dos indivíduos teve que aderir a quarentena, aumentando, assim, a quantidade de horas em casa, ampliando, consequentemente, o consumo de energia e de água, além de uma maior produção de resíduos (Almeida et al., 2020). Os entrevistados do presente estudo, ao serem questionados sobre as medidas utilizadas para proteger o meio ambiente durante o período de isolamento social, relataram que tiveram como iniciativa a economia do consumo de água $(45,70,3 \%)$ e de energia $(44,68,8 \%)$. Entretanto, estes acreditam que durante a pandemia houve aumento do consumo de energia $(36,56,3 \%)$. A conscientização ecológica deve começar dentro da própria casa, com a adoção de algumas medidas sustentáveis básicas como fechar bem as torneiras quando não for mais utilizá-las e diminuir o tempo gasto durante o banho. Essas medidas contribuem para a economia de água, evitando seu desperdício, o que, no cenário atual, é de extrema importância para minimizar os impactos provocados ao meio ambiente (Carvalho et al., 2020).

Para que a coleta seletiva em edificações residenciais ocorra de forma correta, diminuindo os riscos de contaminação dos catadores e das cooperativas, é necessário adotar o processo de separação por quatro grupos principais de materiais recicláveis: papel, plástico, metal e vidro (Almeida et al., 2020). Contudo apenas 16 alunos (25,0\%) referiram separação do lixo descartável. Ademais, nenhum referiu utilização de produtos ecológicos e três $(4,7 \%)$ citaram não realizar nenhuma medida de proteção.

Jardim e Wells (1995) preconizam que, no Brasil, o lixo doméstico é composto, em média, por 3\% de plástico, 3\% de vidro, $4 \%$ de metal, $25 \%$ de papel e, $65 \%$ de matéria orgânica. Cada município possui sua legislação acerca do recolhimento dos resíduos sólidos, no entanto, o lixo comercial e domiciliar de até $50 \mathrm{~kg}$ ou litros é de responsabilidade das prefeituras, enquanto os demais são de responsabilidade do próprio gerador. Ao serem questionados sobre a coleta de resíduos, a maior parte dos estudantes cita que costuma separar o lixo comum de outros lixos tais como pilhas, baterias, eletrodomésticos e óleo de cozinha apenas às vezes $(24,37.5 \%)$. Os estudantes do segundo e terceiro ano acreditam que durante a pandemia houve expansão da produção de lixo doméstico $(\mathrm{p}=0,031)$.

Decerto, o isolamento social teve impactos gerados no meio ambiente, tanto negativos quanto positivos. A Agência Espacial Europeia (ESA), coletou imagens de satélite que revelam uma redução temporária dos níveis de poluição do ar ao redor do mundo durante a pandemia. Ademais, a ESA também detectou uma diminuição da presença de dióxido de nitrogênio (NO2), composto químico que contribui para a poluição atmosférica e para a chuva ácida (Souza, 2020). Nesse contexto, os entrevistados do presente estudo, responderam que nesse momento de isolamento social o seu interesse por assuntos relacionados ao meio ambiente é apenas razoável (32, 50,0\%). Além disso, a maior parte também acredita que durante a pandemia houve diminuição da poluição de rios e lagoas $(41,64,1 \%)$ e do desmatamento $(35,54,5)$, enquanto 50,0\% (n=32) acredita que houve redução da emissão gases. Apenas 14 estudantes $(21,9 \%)$ consideram que a pandemia aumentou a produção no campo.

$\mathrm{O}$ vírus Sars-CoV-2 possui alta taxa de transmissibilidade, em que é realizada através do auto inoculação deste em membranas mucosas e do contato com superfícies inanimadas contaminadas, determinando a necessidade de adoção rápida e preventiva de medidas de proteção humana, visando impedir a contaminação. Isto posto, a OMS classificou a doença causada pelo novo Corona vírus (SARS-CoV-2), COVID-19, como pandemia (Souza, 2020). Durante a pandemia, as medidas mais citadas pelos alunos para prevenção de contaminação com COVID-19 foi manter rotina higiene pessoal (52, 81,3\%), seguido de desinfetar compras $(46,71,9 \%)$, de limpar objetos com álcool 70 (43, 67,2\%) e não compartilhar objetos uso pessoal (37, $57,8 \%$ ). 
Alguns impactos ambientais provocados pelas indústrias reduziram durante a pandemia, dentre eles a redução das emissões de gases que contribuem para as mudanças climáticas e a diminuição na geração de resíduos, visto que muitas empresas pararam temporariamente suas atividades para evitar a disseminação do vírus. Com a paralisação de fabricas e empresas, além das restrições de viagens, houve também redução nas emissões de $\mathrm{CO} 2$, no uso de combustíveis fósseis, de matéria prima e na geração de resíduos (Oliveira et al., 2020). Menos da metade dos estudantes acha que o período de isolamento social interferiu negativamente no meio ambiente $(41,64,1 \%)$. No entanto, acreditam que o aumento da queima de lixo hospitalar não aumenta a produção de $\operatorname{CO} 2(38,59.4 \%)$, o que vai contra a literatura, que descreve que ocorreu uma ampliação da produção de resíduo sólido hospitalar, devido ao maior fluxo de pacientes, expondo a população e o meio ambiente aos riscos do material contaminante sem tratamento. É necessário que os resíduos hospitalares sejam incinerados, o que potencializa a emissão de CO2, segundo a recomendação da Política Nacional dos Resíduos Sólidos (PNRS) (2010) e da OMS (2020) (Souza, 2020).

A educação ambiental, ao ser abordada e elucidada no ambiente escolar promove a criticidade e a sensibilidade do aluno acerca do tema. Um estudo desenvolvido por Santos com 29 alunos mostrou que estes em sua maioria (93\%) responderam positivamente sobre a abordagem do tema no ambiente educacional, demonstrando que esse tema tem significativo enfoque nas escolas brasileiras (Santos et al., 2019). Jacobi (2005) ratifica que para a construção de uma visão crítica é necessária a educação formal, sendo fundamental a problematização e ação em relação aos problemas socioambientais. No presente estudo, a educação ambiental como um tema abordado pela escola foi mencionada por três quartos dos estudantes $(48,75,0 \%)$, contudo a diretora da escola estudada relatou que para os estudantes da $2^{\text {a }}$ série do ensino médio há a disciplina de Educação Ambiental juntamente com Cidadania, ademais eventos como feira de ciências também abordam o tema.

Para a maioria dos estudantes o conceito de meio ambiente se resume aos seres vivos (plantas, animais e seres humanos) e os recursos que a natureza oferece (ar, água, solo e alimentos) (44,68,8\%). Ricklefs (1996) define como meio ambiente o que cerca um organismo, considerando os microrganismos, as plantas e os animais com os quais ele interage, o que corrobora com a maioria das respostas fornecidas pelos estudantes.

Ross e seus colaboradores (2012) afirmam que os problemas econômicos, sociais e ecológicos causados pelo atual modelo de desenvolvimento, em sua maioria, de forma não sustentável, são inúmeros. Ao visar o produto final, o ser humano diversas vezes degrada o meio ambiente através do desgaste dos solos, da poluição do ar e da água e da não economia de energia, colocando em risco o próprio desempenho dos sistemas humanos. Ao serem questionados sobres quais atitudes são adotadas para contribuir com o cuidado do meio ambiente, a maioria do público estudado relatou que tem atitudes como não contaminar solo $(44,68,8 \%)$ e não gastar muita energia $(45,70,3 \%)$, no entanto apenas dois alunos $(3,1 \%)$ relataram não gastar muita água e cinco $(7,8 \%)$ referiram não agredir o meio ambiente. $O$ estudo de Bezerra teve como resultado que a maioria dos estudantes não contaminava o solo, nem consumiam muita energia elétrica (Bezerra et al., 2014), achados semelhantes aos encontrados na pesquisa. Dessa forma, observa-se relevante grau de conscientização de alguns estudantes em relação à importância de se preservar o meio ambiente. No entanto, a não economia de água relatada demonstrou a necessidade desse tema ser mais amplamente debatido na escola, tal como a importância de não agredir o meio ambiente.

O consumo de água e energia elétrica está diretamente relacionado com a percepção ambiental e os custos de aquisição inerentes às residências. Praticar o consumo consciente em uma sociedade moderna, onde o consumidor é envolvido por diferentes tipos de tecnologias, que proporcionam conforto e rapidez para a realização das atividades do cotidiano, torna-se uma tarefa de difícil execução (Fournier et al., 2015). Ao serem questionados sobre ao sair do banheiro ou do quarto, a maioria dos alunos cita apagar a luz $(55,85,9 \%)$, demonstrando consciência ambiental. 
A degradação ambiental é caracterizada pela deterioração do ambiente através dos de seus recursos. No Brasil, podese mencionar como exemplos a poluição da água, do ar e do solo e a deposição inadequada dos resíduos sólidos. A água é um meio mais propícios para o transporte de patógenos, sejam eles protozoários, vírus ou bactérias. A ausência de saneamento básico nas cidades brasileiras e a carência do acesso à água isenta de microrganismos causadores de patologias contribuem para que haja mais de 5 milhões de óbitos por ano (Barboza et al., 2016). Conhecer o destino correto da água é relevante para que haja uma conscientização mais expressiva da população, evitando o seu desperdício e sua contaminação. A maioria dos alunos não sabe o que ocorre com a água após sua utilização $(26,40,6 \%)$, sendo a maioria destes da primeira série do ensino médio ( $\mathrm{p}=0,011$ ), isso denota a necessidade de serem adotados mais oficinas temáticas que informem aos alunos acerca do destina da água e contribua para seu consumo consciente.

Adotar um desenvolvimento sustentável, é, em síntese, implantar medidas a partir de uma lógica em que as necessidades presentes do ser humano sejam satisfeitas sem o comprometimento, portanto, da capacidade de satisfazer as necessidades das gerações futuras (Ross et al., 2012). Um estudo de Bezerra e seus colaboradores em 2014 acerca da sustentabilidade, coletou dados em que todos os alunos do $6^{\circ}$ ano informaram não saber o que é um desenvolvimento sustentável. Na presente pesquisa, a maior parte dos estudantes sabe o que significa a expressão "desenvolvimento sustentável" $(42,65,6 \%)$, sendo que nenhum estudante da primeira série refere esse conhecimento ( $\mathrm{p}=0,001)$, essa diferença de relação entre os dois estudos pode estar relacionada com a idade dos estudantes, visto que o estudo teve como público estudantes do ensino médio, em que há maior maturidade.

A maioria dos alunos também sabe o que é coleta seletiva de resíduos sólidos $(46,71,9 \%)$ com concentração desse nível de conhecimento dos estudantes da segunda e terceira séries $(\mathrm{p}=0,037)$, o que confirmou os resultados obtidos por Bezerra et al., ao realizar o mesmo questionamento e obter a maioria das respostas positiva. A maioria das escolas estimulam dentro do ambiente educacional a coleta seletiva, o que contribui para que esse hábito também seja realizado em casa.

A contínua produção de resíduos sólidos é resultado direto do consumo cotidiano de produtos industrializados. A produção de lixo nas cidades é de tal ímpeto que é necessário considerar a problemática gerada pelos resíduos sólidos, desde a etapa da geração até a disposição final, para conceber uma cidade (Mucelin et al., 2008). A maioria dos estudantes acredita que o que diferencia o lixo de poluição é que a poluição é causada por indústrias, carros e máquinas e lixo é produzido pelo ser humano $(28,43,8 \%)$ ou que a poluição é lixo colocado na natureza e lixo é qualquer tipo de resíduo $(23,35,9 \%)$.

\section{Conclusão}

O conjunto de atividades vivenciadas pelos alunos de Ensino Médio de uma Escola Estadual de Fortaleza-CE, propiciada pelo Programa de Iniciação Científica no Ensino Médio, permitiu fazer importantes reflexões sobre o impacto da pandemia pela COVID-19 em relação a temática de sustentabilidade ambiental. Foram elaborados materiais de cunho educativo contextualizando práticas desejáveis relativas à sustentabilidade ambiental, tanto em um contexto geral como direcionado ao gerenciamento de resíduos odontológicos. Ademais, a análise situacional sobre a percepção de alunos do Ensino Médio sobre sustentabilidade ambiental permitiu observar que os escolares apontaram importantes reflexos ocasionados pela pandemia decorrente do novo coronavírus.

\section{Agradecimentos}

Programa de Iniciação científica Ensino-médio da Universidade Federal do Ceará. 
Research, Society and Development, v. 10, n. 7, e8910716271, 2021

(CC BY 4.0) | ISSN 2525-3409 | DOI: http://dx.doi.org/10.33448/rsd-v10i7.16271

\section{Referências}

Barbosa, D. A. F., Lima, R. M., Menezes, L. S., Cavalcante, D. S., Brito, G. G., Cid, A. M. P. L., Silva, P. G. B., Carvalho, F. S. R., Aguiar, A. S. W., Kurita, L. M., \& Costa, F. W. G. (2020). Sustentabilidade ambiental no contexto da Iniciação Científica no Ensino Médio: uma ação estratégica frente ao gerenciamento de resíduos do processamento químico de radiografias odontológicas. Revista Brasileira De Educação Ambiental (RevBEA), 15 (3), 92-114.

Barboza, L. A. S., Brasil, D. S. B., \& Conceição, G.S. (2016). Percepção ambiental dos alunos do $6^{\circ}$ e do $9^{\circ}$ anos de uma escola pública municipal de Redenção, Estado do Pará, Brasil. Revista Pan-Amazônica de Saúde, 7(4), 11-20.

Bezerra, Y. B. de S., Pereira, F. de S. P., Silva, A. K. P. da, \& Mendes, D. das G. P. da S. (2014). Análise da percepção ambiental de estudantes do ensino fundamental II em uma escola do município de Serra Talhada (PE). Revista Brasileira De Educação Ambiental (RevBEA), 9(2), $472-488$.

Brasil. Conselho Nacional do Meio Ambiente. Resolução Conama n 358, de 29 de abril de 2005. Dispõe sobre o tratamento e a disposição final dos resíduos dos serviços de saúde e dá outras providências. Brasília, DF: Diário Oficial da União no 84, de 4 de maio de 2005; Seção I, p. 63-5.

Carvalho, N., Ribas, M., Carvalho, T., \& Barcellos, A. (2020). Percepção ambiental de alunos do ensino fundamental no município de Tupanciretã/RS. Revista Monografias Ambientais, 1, e7.

Cruz, M. M. da. (2012). Avaliação: conceitos e métodos. Cadernos de Saúde Pública, 28(7), 1414-1415.

Dias, M. A. R. (1993). Meio ambiente e comunicação-a função das universidades. Educação brasileira, Brasília,15(31), 117-135.

Estrela, C. (2018). Metodologia Científica: Ciência, Ensino, Pesquisa. Editora Artes Médicas.

Hocevar, C. M., \& Raya-rodriguez, M. T. M (2002). Avaliação do impacto ambiental gerado por efluentes fotográficos, gráficos e radiológicos em Porto Alegre, RS, Brasil. Engenharia sanitária e ambiental: órgão oficial de informação técnica da ABES, Rio de Janeiro, 7(3/4) 139-143.

Jacobi, P. M. (2005). Educação ambiental: o desafio da construção de um pensamento crítico, complexo e reflexivo. Educação e Pesquisa, 31(2), 233-250.

Jardim, N. Z. et al (1995). Lixo municipal: manual de gerenciamento integrado. IPT/Cempre.

Massi, L. Q., Salete, L., \& Dinham, R. (2010). Estudos sobre iniciação científica no Brasil: uma revisão. Cadernos de Pesquisa, 40(139), 173-19.

Mucelin, C. A., \& Bellini, M. (2008). Lixo e impactos ambientais perceptíveis no ecossistema urbano. Sociedade \& Natureza, 20(1), $111-124$.

Oliveira, A. C. de, Lucas, T. C., \& Iquiapaza, R. A. (2020). O que a pandemia da covid-19 tem nos ensinado sobre adoção de medidas de precaução? Texto \& Contexto - Enfermagem, 29, e20200106.

Oliveira, M. N., Campos, M. A. S., \& Siqueira, T. D. C. (2020). Coronavírus: globalização e seus reflexos no meio ambiente. BIUS-Boletim Informativo Unimotrisaúde em Sociogerontologia, 20(14), 1-12, 2020.

Ricklefs, R. E. (1996) A economia da natureza. In: A economia da natureza, 470-470.

Rohlfs, D. B. et al. (2011. A construção da Vigilância em Saúde Ambiental no Brasil. Caderno e Saúde Coletiva, 19(4), 391-398.

Segre, M., \& Ferraz, F. C. (1999). O conceito de saúde. Rev. Saúde Pública, 31(5), 538-542.

Santos, A. E. S., Roch, V.S., \& Oliveira, K. P. L. (2019). Avaliação da percepção ambiental em uma amostra de escolares no município de Nova PalmeiraPB. Revista Craibeiras de Agroecologia, 4(1),76-78.

Souza, L. P. (2020). A pandemia da COVID-19 e os reflexos na relação meio ambiente e sociedade. Revista Brasileira de Meio Ambiente, 8(4) 2020.

Teschke, K., Chow, Y., Brauer, M., Chessor E., Hirtle, B., Kennedy, S. M., Yeung, M. C., \& Ward, H. D. (2002). Exposures and their determinants in radiographic film processing. AIHA $J$ (Fairfax, Va), 63(1):11-21. 